\section{Downs: The History of a Disability}

David Wright. Oxford University Press, 2011. 239 pages. $\$ 24.95$ (US), hardcover.

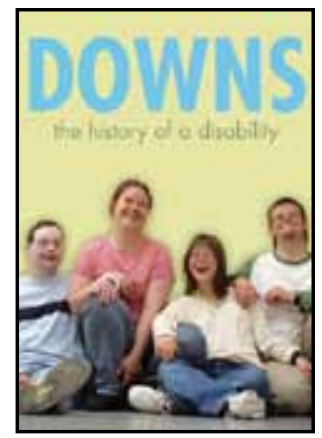

One of my early memories (E.P.) is of holding my mother's hand while walking through Eaton's department store in Hamilton, Ontario (where the elevators still had human operators), and passing another boy and his mother in the crowd. I then turned to my mother and said, "We know him. Where have we seen him before?" I was told that the boy was "Mongoloid," and that children who had this disability bore similar facial features, and that we had not actually met him before. My father, being a doctor, later even explained about the extra chromosome (most of which I did not understand).

This anecdote can now be put into its correct historical context: Down's Syndrome does have a recognizable phenotype, although it took years to categorize; the Mongoloid label still persisted during the 1970s in Commonwealth countries despite the disorder's having become an eponymous syndrome in honour of John Langdon Down; and the disability's karyotype does indeed possess a trisomy of chromosome 21 .

Professor David Wright's Downs: The History of a Disability is an elegantly written history of intellectual disability in general, and an admirable treatment of Down's Syndrome in particular. The story stretches from early modern Europe and colonial America, including the legal status of "individuals who were incapable of governing their own affairs" (page 18), through the description of the various physical features of the syndrome, to the social history of asylums, eugenics, "mainstreaming" in education, and amniocentesis and abortion.

The prose is lucid, the quotations well-chosen, and the sources expertly marshaled. The reader is clearly enjoying the labours of a professional historian who, nevertheless, is writing for the educated public, not a narrow academic or medical audience.

Wright seeks to investigate both "the medical and social history of Down's Syndrome" and thus examine the "fascinating scientific history" while retaining personal experiences of the disability as well as the changing societal views of it (page 15). He is largely successful. One thread of the text follows the doctors and scientists who observed and categorized epicanthal folds and simian creases and who proposed theories of why the offspring of English couples bore resemblances to "Mongol races," and who eventually determined that an extra chromosome was to blame; the other thread follows how society viewed and treated its members with intellectual disabilities. This included debates over the utility of educating those with Down's Syndrome, practices like involuntary sterilization and eugenics, as well as educational mainstreaming, abortion, and the formation of groups aimed at helping parents cope.

In addition to the above two threads and the basic chronological narrative, the book provides some excellent potted histories of related subjects. For example, embedded in the chapter, "The Simian Crease," which deals largely with the early twentieth century, Wright provides a three-page history of intelligence testing (pages 94-97). And while a major theme in the book is the change in naming from "Mongolism" to "Down's Syndrome," showing as it does the racial theories and cultural trends popular over time, Wright allocates space in chapter 4 to whether "Down" or "Down's" should be used, and even whether the apostrophe should be eliminated altogether (as his editors apparently decided for the book's title). Such details are what good history is about.

I have two criticisms of the book. The first is that, while Wright succeeds in his goal of providing social and not just medical history, he has not fully succeeded in his goal of keeping it personal. As in much historical writing (other than biography), trends eclipse personalities. The Down family gives promise of being quite interesting but, apart from a mysterious tale about two of the brothers having a fight where one is "struck in the groin by a wood chisel" and dies (page 79), they come off as quite banal, rousing neither admiration nor revulsion for their Victorian accomplishments. And if ever there was an eccentric polymath it was Dr. Lionel Penrose, who designed children's puzzles, played chess, and loved mathematics (and was a psychiatrist who studied developmental disabilities); he is, however, portrayed here as another two-dimensional figure in the history of cytogenetics. If the book is meant for a lay audience, it could be more colourful without risking being sensational.

This leads to my second criticism. Jerome Lejeune, the French geneticist, gets his most interesting treatment in the conclusion to chapter 4 . It is only here that we learn he was first a "modest country doctor," that the discovery of the genetic basis of Down's was full of "intrigue," and that he was nominated for beatification in 2004. If lawyers 
and essayists are not supposed to introduce new evidence in the summation or conclusion, Wright should not consistently save so much new information for his chapter conclusions - and often the most interesting information at that. Another example of this is the conclusion to chapter 3. Wright here describes society's "manufacture" of the "feeble mind," writing that some have seen it as a "manifestation of the rise and cult of education, individualism, and intelligence that has dominated Western society for the last hundred years" (page 113). It was not clear from the preceding 30 pages that this was the theme, although it sounds most interesting.

Is this book a good read for a child and adolescent psychiatrist? Of course. To know the history of any disorder seen in clinic is most valuable. The reading of history should not need to be justified. Only whether the history in question is told well should be evaluated. David Wright tells the history of Down's Syndrome well: it is accomplished with erudition, empathy, and good prose.

\section{Eric Prost MD, FRCPC}

Queen's University

Kingston, Ontario

\author{
Nasreen Roberts, MBBS, FRCPC \\ Queen's University \\ Kingston, Ontario
}

\section{Complete Mental Health: The Go-to Guide for Clinicians and Patients}

John Ingram Walker. W.W. Norton \& Company: New York, NY, 2010. 372 pages. \$34.50, softcover.

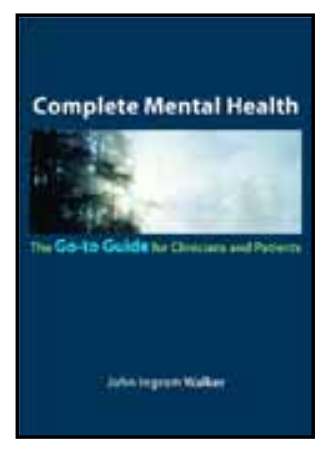

Complete Mental Health: The Go-to Guide for Clinicians and Patients is a review of psychiatric diagnosis and treatment. Dr. Walker ambitiously targets a readership which includes not only primary care and mental health clinicians but also patients and other lay readers. That said, as we began reading this book, it was not immediately clear who its most fitting target audience was.

Dr. Walker begins the book's first chapter by recounting an interaction with his granddaughter involving a matchstick boat competition in a stream. A parallel is drawn between the unpredictable course of a matchstick boat down a stream and the unpredictable nature of our lives. With this example, the author introduces the view that both nature and nurture contribute to one's life experiences. He continues the chapter by explaining classifications of personality disorders and how a number of psychological theories explain normality of behaviour. The chapter ends with a number of tables that describe self-report approaches to assessing flexibility, confidence, maturity and personability.

The author subsequently guides the reader through a total of seventeen chapters, each covering details of a psychiatric disorder category in the DSM-IV-TR classification, and its related psychopharmacology and psychotherapy. Dr. Walker illustrates the various disorders with references to pop culture or to his own clinical and non-clinical life experiences. The clinician quizzes at the end of each chapter help to highlight important points. The tables and checklists provided in each chapter come in handy as quick references. A limitation of the rating scales is the absence of detail regarding their psychometric properties.

The book is practical and certainly easy to read. Dr. Walker employs a great deal of humour throughout this work. Though perhaps not intended to be off-putting, at times his humour may be perceived as so by patients and their loved ones. An example of such humour is the table on page 24 titled "Bedlam Christmas Carols From Cyberspace" with descriptions such as, "Schizophrenia, 'Do you hear what I hear?",

Dr. Walker covers child and adolescent disorders in one chapter. The general overview provided on clinical features and treatment may suffice for those who treat children and adolescents infrequently, but not for those who work with mentally ill children and adolescents on a recurring basis.

The author's descriptive style vacillated between being too simplistic for healthcare providers at one extreme and too scientifically complex for the lay person at the other extreme. For example, in Chapter 15: The Uses and Abuses of Psychiatric Medications: Pills, Poisons, and Placebos, Dr. Walker begins to describe neurotransmitters using an analogy of houses and electricity and within the next few pages, shifts to an increasingly complex description of specific medications and their neurotransmitter effects.

Dr. Walker concludes this volume with a chapter focused on strategies to make changes to overcome mental or emotional illness. There is a description of factors which militate against such change and those that promote it. The chapter ends with an explanation of practical methods to achieve change.

In summary, Complete Mental Health: The Go-to Guide for Clinicians and Patients is a good resource for clinicians wishing to learn the basics of mental health 